\title{
Crítica da educação e da escola sob o prisma da arte literária nos ensaios do escritor Bartolomeu Campos de Queirós (1944-2012)
}

\section{Criticism of education and school under the prism of literary art in the essays of writer Bartolomeu Campos de Queirós (1944-2012)}

\author{
Matheus da Cruz e Zica*
}

\section{RESUMO}

Um dos pressupostos dessa pesquisa é que o literato Bartolomeu Campos de Queirós (1944-2012) produziu um pensamento crítico engajado nas ocasiões em que foi convidado a tratar publicamente de seu processo de escrita e de suas memórias de professor, aluno e leitor. Mineiro do interior, ao longo de sua trajetória biográfica publicou mais de 60 livros, sendo a maioria de natureza literária. O objetivo específico desse artigo é indagar sobre o uso de seu lugar de fala como escritor para lançar provocações ao modo como se tem constituído as relações entre arte, educação e escola em alguns dos principais textos críticos que produziu ao longo das décadas de 1980,1990 e 2000.

Palavras-Chave: História Intelectual. Arte e Educação. Escola. Crítica da Cultura.

\begin{abstract}
One of the presuppositions of this research is that the literary Bartolomeu Campos de Queirós (1944-2012) produced an engaged and critical thought in the occasions in which he was invited to publicize themes as his writing

*Universidade Federal da Paraíba. João Pessoa, Paraíba, Brasil. E-mail: matheusczica@ gmail.com . https://orcid.org/0000-0003-1195-948X.
\end{abstract}


process and his memories of teacher, student and reader. Such writer is from the interior of Minas Gerais and throughout his biographical trajectory he published more than 60 books, most of them belonging to literature genre. The specific objective of this article is to inquire about the use of his speech as a writer to launch provocations to the way in which the relations between art, education and school have been constituted in some of the main critical texts that he produced throughout the decades of 1980, 1990 and 2000.

Keywords: Intellectual History. Art and Education. School. Cultural Critic.

\section{Introdução}

Para falarmos da relação entre arte e educação consideramos necessário, antes mais nada, precisarmos melhor teoricamente alguns termos. Para entendermos o lugar fundamental da educação e da escola para os seres humanos recorremos à Hanna Arendt 2005), para quem o próprio ato de humanizar-se se confunde com of formar-se.

Quais seriam as bases epistemológicas que justificariam a diferenciação entre, de um lado, aquilo que os humanos orgulhosamente passaram a chamar de modo de vida em cultura e, de outro, o reino animal, ora lembrado por uma suposta anomia, ora demarcado como vítima dos automatismos repetitivos dos condicionamentos genéticos das espécies? Tratamos aqui das fronteiras do que se considera ser um humano. Colocada de outro modo por Hanna Arendt (2005) a questão seria a seguinte: afinal de que falamos quando nos referimos à Condição Humana?

Hanna Arendt afirma que compartilhamos com os animais o fato de que nascemos para a vida. É a transformação natural, genética, biofísica e orgânica que representa a vinda de um novo ser ao universo dos vivos. Desse ponto de vista, podemos dizer que assim como um gato um ser-humano tem natalidade. Entretanto, diferente dos demais seres vivos, os humanos precisarão de um segundo parto: precisarão de nascimento, após a natalidade. Além de surgirem para a vida necessitarão de nascerem para o mundo. Enquanto o conceito de vida englobaria todas as esferas biofísicas que nos ligam aos animais e aos demais elementos naturais, o conceito de mundo viria a configurar exatamente o que seria específico dos humanos, referir-se-ia ao acumulado de linguagens, símbolos, normas e técnicas que são transmitidos de uma geração a outra.

Justamente daí viria o drama de toda a condição humana: somos passíveis de não nos humanizarmos caso as condições culturais e sociais necessárias para 
que isso ocorra não se apresentem, mesmo que nosso arcabouço biológico ofereça as condições necessárias para tal. Se não houver comprometimento rigoroso de uma geração para com a outra, de um setor social específico para com os demais, esse acumulado representado pelo mundo humano pode ser desfeito, abandonado, esquecido, negligenciado e, em última instância, descartado.

Um dos principais meios pelos quais os homo sapiens se tornam humanos é por via da criação e do intercâmbio de símbolos através dos quais elaboram as suas experiências, engendrando um panorama favorável para que se associem e que não se matem aleatoriamente por conta de discordâncias corriqueiras. Tendemos a valorizar as línguas como os meios principais pelos quais os seres humanos conseguem gerenciar os seus acordos e desacordos no afã de afastarem a violência física do cotidiano de suas esferas culturais, garantindo a manutenção das experiências bem-sucedidas acumuladas na caminhada coletiva que empreendem. $O$ terreno fundamental da transmissão desse mundo comum herdado é o da educação e o lócus principal engendrado pela modernidade para essa transmissão se convencionou como sendo a escola.

O problema é quando se chega a conceber que educação seria um mero repasse de informações de uma geração à outra, ingenuamente acreditando que a tradição existe por si só, negligenciando o aspecto eminementemente seletivo de qualquer operação sobre o conhecimento do passado acumulado (OLIVEIRA, 2014). Segunda questão que ao nosso ver parece extremamente problemática é a de se tomar a educação como mera transmissão de conhecimentos letrados bem definidos, excluindo os corpos e as subjetividades dos processos de formação que ocorrem na escola.

$\mathrm{O}$ retorno às grandes referências fundantes da Pedagogia Católica nos mostra que o entendimento da função da escola como transmissão de conhecimento letrado herdado coincide com o que Santo Tomás de Aquino defendia em seu De Magistro, em pleno século XIII (LOPES, 1998). Ao contrário de Santo Agostinho que, em sua obra de mesmo título, De Magistro, já no século IV defendia não haver mestres exteriores, cada um encontrando por si e em si o que é verdadeiro. Para Aquino, novecentos anos depois, a exterioridade toma relevo. Em contraposição à interioridade agostiniana, o ideal de "mestre iluminado", aquele que tem o segredo, passa a tomar a cena a partir da reflexão de Aquino.

Essa concepção parece ter se fortalecido no pensamento pedagógico leigo nascente e se espraiou pelos séculos afora. Foi assim que também chegamos ao triunfo do conteudismo, em detrimento de um foco nas práticas de si. O Mestre de Aquino não é necessariamente aquele que, por percorrer uma longa jornada de si, pode enfim falar de suas experiências aos discípulos. O Mestre de São Tomás é aquele que leu, aquele que aprendeu os conteúdos.

Em meio a esse amplo debate de fundo que atravessa a educação é que a 
urdidura textual do escritor Bartolomeu Campos de Queirós vai se entretecendo e produzindo novos sentidos para antigas indagações.

Tenhamos atenção ao que Campos de Queirós defendeu com seu ato de fala (SKINNER, 1996) em intervenção pública na II Conferência Brasileira de Educação, nas dependências da Universidade Federal de Minas Gerais, em 1982, ainda em tempos de ditadura.

Quando penso numa escola democrática, ignoro propositalmente número de vagas e de matrículas. Penso na ação pedagógica democrática. Considero seu objetivo, enquanto democrática, o de fazer com que o sujeito se inclua num lugar que é sociedade e linguagem, lugar onde, em verdade, ele já está inserido. Sua função (da escola) seria de deixar o sujeito se significar, e não ser apenas significante ou objeto de experimentação de novas metodologias sem alterar valores. Uma escola democrática não outorga ao sujeito o direito a uma linguagem que já está inscrita nele, mas ele deve falar e conquistar o seu lugar. (QUEIRÓS, 1982 [2012], p.110)

Há tempos a escola foi inflada de cargas discursivas externas às reais necessidades dos sujeitos. Literalmente presa na grade curricular é fácil verificar que ainda hoje não há na escola atual o importante espaço e tempo destinados ao vazio. Vazio útil e necessário, principal responsável por tornar possível o brotar de um conteúdo genuíno proveniente das subjetividades.

O desprestígio da Educação Artística e da Educação Física nas escolas brasileiras que caracteriza a história recente das disciplinas escolares em nosso país (SOUZA JÚNIOR \& GALVÃO, 2005), da carga horária inferior à falta de critério na escolha dos professores dessas disciplinas, nos indica que a tradição subterrânea conteudística que vem de séculos ainda continua a nos atormentar.

Uma das lutas internas nas discussões sobre pedagogia hoje é pela valorização de uma dimensão educativa que não se pretende toda, completa, suficiente, atracada à certeza de um conteúdo. Defesa de uma dimensão educativa que esteja mais próxima, portanto, da insuficiência dos signos apontada por Santo Agostinho, e mais distante, por conseguinte, das tentativas ambiciosas de tamponá-la ou suturá-la conforme as empreendias por Tomás de Aquino (LOPES, 1998, p.63).

Do outro lado estaria a escola autoritária assim por ele concebida, de acordo com sua fala na mesma II Conferência Brasileira de Educação, no ano 1982: 
Faz-me pertinente explicitar uma inquietação atual minha: se a escola está inserida na sociedade, ela reflete a sociedade. Mas ao conferir esta sociedade verifica-se que a infelicidade reside largamente na alma humana. Infelicidade que é compensada pelo ideal do consumo. Caberia então à escola o desencadeamento de uma reflexão no sentido de conquistar a felicidade perdida, e não preparar o aluno para adquirir os objetos de compensação, sem cogitar valores. (QUEIRÓS, 1982 [2012], p.109)

Bartolomeu ataca aqui não apenas o aspecto do autoritarismo do governo militar, mas a pobreza humana que tal regime provocava no sentido de empurrar os sujeitos para as relações com o consumo de objetos, em detrimento da qualificação das relações sociais. Autoritarismo e capitalismo teriam portanto uma relação muito próxima na avaliação do autor. Tanto um quanto o outro seriam conjuntamente os opositores principais em relação ao enorme e mais nobre potencial que a educação teria, em sua visão: o do cultivo das subjetividades para uma vida plena no espaço público.

Campos de Queirós fazia, portanto a crítica à escola daquele momento, percebendo-a como um espaço de controle, um microcosmo do clima instituído no país com a ditadura militar. Para reverter o quadro propunha uma radicalização da arte na escola, fazendo coincidir em seu construto teórico Literatura e Política:

No espaço autocrático (na escola), o único momento de democracia está quando se dá a relação do sujeito com a arte. Tudo o que está ausente na autocracia, ou seja, a liberdade de expressão do desejo se concretiza. A expressão artística ultrapassa o autor e se efetiva como plural, como coletiva, portanto democrática, na medida em que se elimina o próprio sentido de feitor e consumidor, de proprietário e propriedade. Ela é democrática enquanto, mesmo no silencio, ela configura a convivência. Assim, quero crer que, independentemente de estar em qualquer espaço ou regime político, a literatura, enquanto literatura, será sempre o exercício da democracia, porque como arte ela mesma estabelece o seu lugar.Tal discurso tem como proposição final estabelecer a literatura como luta democrática. E na escola, onde leitura e escrita são o motor de toda aprendizagem, o discurso da educação poderia ser o da literatura, na medida em que a verdade está justamente na fragilidade que se deve atribuir ao conhecimento humano. (QUEIRÓS, 1982 [2012], p.109-110) 
Não seria irrelevante levantar a hipótese de que essa crítica à escola da ditadura de 1964 parecia carregar ecos de um desconforto mais antigo do autor em relação ao espaço escolar... Desconforto em relação à escola que ele mesmo frequentou em sua infância durante a década de 1950, ao que parece herdeira em muitos pontos de outra ditadura, a de Getúlio Vargas, que durou de 1937 a 1945, conforme veremos.

O próprio Bartolomeu C. Queirós disse certa vez que: "A infância é o nó inicial para se estabelecer uma trama que perdura pela existência" (2007 [2012], p.80). Seguindo esta sua indicação fomos buscar por suas memórias. Instado por Fanny Abramovich a escarafunchar sua infância, no texto "Foram muitos, os professores", que consta na coletânea "Meu professor inesquecível: ensinamentos e aprendizados contados por alguns de nossos melhores escritores", de 1997, B. C. de Queirós vai se lembrar mesmo é de seu avô.

Meu avô, arrastando solidão, escrevia nas paredes da casa. As palavras abrandavam sua tristeza, organizavam sua curiosidade silenciosamente. Grafiteiro, afiava o lápis como fazia com a navalha. A cidade era seu assunto: amores desfeitos, madrugada e fugas, casamentos e traições, velórios e heranças. (...)Eu restava horas sem fim, de coração aflito, seduzido pelas histórias de amor, de desafeto, de ingratidão, de mentiras do meu primeiro livro - as paredes da casa do meu avô. Assim, percebi o serviço das palavras - facas de dois gumes. Meu avô desdizia verdades eternas com as mesmas palavras com que escreveram a Bíblia Sagrada (...). Essa sua capacidade de negociar com as palavras, de buscar seus avessos me atordoava e seduzia.(...) suas paredes mais se enchiam de avisos sobre o mundo e as fronteiras do mundo. Eu decorava tudo e repetia timidamente. Eram tranquilas suas aulas, e o maior encanto estava em meu avô cultivar as dúvidas. (...) Às vezes ele me pegava esticando o pescoço, tentando alcançar um pedaço mais longe, um parágrafo mais alto. Ele me apontava a cadeira. Eu buscava e ele me ajudava a subir. (...) Meu avô devia supor que escola fosse o mundo inteiro, a vida inteira, com noite e dia, perdas e ganhos, dores e tristezas, sonos e sonhos. (QUEIRÓS, 1997 [2012], p.19-21)

Em meio à ironia divertida cultivada pelo avô, as palavras surgem para o menino Bartolomeu como possibilidade viável para o prazer. Palavras que permitiam a aproximação com as incongruências do real, com as impossibilidades da razão e com os dramas da vida. Não para com elas erigir artificialismos, conforme Bartolomeu criança já parecia desconfiar. Com o avô, o Bartolomeu 
menino podia estar consigo mesmo. Não havia Ideal de Eu vindo como voz de comando de uma demanda externa.

Hoje sabemos muito bem que os modelos pedagógicos que reforçam a necessidade de adequação dos sujeitos diversos ao estereótipo único do aluno exemplar, na adultez são desdobrados em outros modelos de ser não menos poderosos divulgados: na mídia, pelos filmes de sucesso; no trabalho, pelo quadro estampando a foto do empregado número 1 do mês pelo recorde de vendas... Todos eles alimentados pela promessa do sucesso, da recompensa a ser fornecida pela instituição, por um outro que ocupa um lugar de poder.

É o perigo da identificação de sujeitos tão diversos entre si com uma imago fantástica e singular da coerência e da viabilidade de se alcançar um Ideal de Eu. Estamos aí diante do fracasso da pedagogia moralizante tradicional que ainda, lamentavelmente, parece vigorar. Quanto maior investimento se faz nesse Ideal de Eu, que não passa de um fantasma produzido pela cultura de um tempo, estranho portanto à singularidade que marca a subjetividade de cada ser humano, mais fraca é a sensação de satisfação de quem assim o promove.

E se a escola do avô era "o mundo inteiro", sem simplificações ou reduções em nome de uma incapacidade das crianças, a escola formal vai parecer um pesadelo para o autor que assim recorda:

Meu avô poderia ter sido meu primeiro professor se fizesse plano de aula, ficha de avaliação, tivesse licenciatura plena. $O$ fato é que ele não aplicava prova, não passava dever de casa nem brincava de exercício de coordenação motora. Minha coordenação motora, eu desenvolvi andando sobre muros ou pernas de pau, subindo em arvores, acertando as frutas com estilingue ou enfiando linha na agulha para minha avó chulear.(...) Mas acreditava, e hoje ainda mais, não ser a casa de meu avô uma escola. Ela não possuía cartazes de cartolina nas paredes, vidro com semente de feijão brotando, cantinho de leitura com livrinhos infantis, lista de ajudantes do dia, tanque de areia, palhacinho de isopor, flanelógrafo de feltro verde. (...) Meu avô não usava toquinhos coloridos, tampinhas de garrafa, palitos de picolé nem me exigia uniforme. Ele nunca me convidou para fazer "rodinha". (...) Meu pai olhava e repetia sempre: "Menino, deixe de inventar histórias, você não sabe ler, nunca foi à escola" ou "Menino, deixe esse papel e vá procurar serviço melhor para fazer". Passei a duvidar da escola. Parecia-me um lugar só para dar autorizações. Se a escola não autorizasse, eu não poderia saber. O medo desse lugar passou a reinar em minha cabeça. (...) Mas logo me veio a ideia: quando entrar para a escola, eu faço de conta que esqueci tudo e começo a aprender de novo. "Uma mentirinha é um santo remédio para botar um ponto final em conversa fiada", me ensinou meu avô, coisa que comecei 
a praticar para encurtar perguntas e me livrar de incômodos.Cheguei de uniforme novo costurado pelo carinho de minha madrinha. O caderno era Avante, com menino bonito na capa, sustentando uma bandeira com um Brasil despaginado pelo vento. Menino rico, forte, com sapatos e meias soquete. $\mathrm{O}$ estojo de madeira estava completo: dois lápis Johann Faber com borracha verde na ponta e mais um apontador de metal. Um copo de alumínio, abrindo e fechando como o acordeom de Mário Zan, completava as exigências da escola.Só minha cabeça andava aflita para esquecer. E esquecer é não existir mais. Isso não é tarefa fácil para quem aprendia em liberdade, escolhia pelo prazer, guardava pela importância. (QUEIRÓS, 1997 [2012], p.20-21)

Escola de apetrechos, de exigências, de instituições de modelos idealizados, de classificação, de artificialidade, de silenciamento dos desejos singulares de cada sujeito... É a escola da qual se lembra B. C. de Queirós. E contra ela lutou em sua adultez.

Já na década de 90, mais especificamente em 1991, na ocasião do III Encontro Estadual do Projeto Biblioteca/Vídeo Escola, o escritor teve a oportunidade de aprofundar a dimensão de sua crítica em relação à conexão automática entre Educação e Escola.

Educação, a palavra, e consequentemente sua extensão, tem sido confundida no país como hábito escolar. Melhor pensando, este processo seria o de criar condições para que o sujeito venha apoderar-se de seus atributos humanos, de sua dignidade. Há que se ter a confiança na capacidade do sujeito de construir a si mesmo. A educação não é um processo raso, linear. Há que concorrer para que o sujeito, ao dobrar-se sobre si mesmo, refaça sua própria face. Ver quem ele é e desejar-se em outros vértices. O processo tem que perpassar o homem. Para tanto, todos os outros animais da natureza são adestrados, e só o homem pode se educar. Pensar sobre si mesmo. Alterar-se à luz de seu desejo. (QUEIRÓS, 1991 [2012], p.101-102)

Há uma conexão muito forte dessas palavras do escritor mineiro com o que Michel Foucault definiu como o pleno processo do cuidado de si. Se em "História da Loucura" (1984 [1975]) e em "Vigiar e Punir" (1978 [1972]) o filósofo francês pensava nos controles implacáveis exercidos sobre os sujeitos por instancias impessoais, a partir da escrita de sua "História da Sexualidade" (Vol.I, 1980 [1976]; Vol.II, 1985 [1984]; Vol.III, 1998 [1984]) Foucault passa a 
considerar as possibilidades de liberdade que estariam alojadas em cada corpo humano. Sendo a sexualidade não redutível aos discursos, através das pesquisas que fez sobre práticas de sexualidade no mundo antigo greco-romano, o exercício da sexualidade passa a ser entendido pelo autor como uma possível prática de liberdade e autoconhecimento por todos os sujeitos.

Das investigações sobre sexualidade no universo greco-romano de mais de 2.000 anos atrás, o pensador francês chega então ao grande tema do cuidado de si, que seria a tônica do pano de fundo cultural que perpassou a experiência histórica dos sujeitos que viveram entre o ano 500 a.C. até aproximadamente 500 d.C, trabalhado com maestria em sua "Hermêutica do Sujeito" (1982 [2011]). Na verdade, descobrira que o exercício da sexualidade como prática de liberdade fazia parte desse arcabouço bem maior que significava a epiméleia heautoû ("cuidado de si"). Muitas vezes também compreendido como cultivo de si, o cuidado de si tinha como imperativo várias práticas de si que teriam como fim a constituição da vida como uma obra de arte (Foucault, 1982 [2011]).

Ainda na referida palestra de 1991, através de referências nesse caso implícitas à psicanálise e à filosofia, Bartolomeu Campos de Queirós procura fortificar esses argumentos que dialogam com sua percepção de mundo enquanto escritor literário e do que vislumbra para a humanidade, esta tomada enquanto projeto, enquanto possibilidade:

O homem é um ser em luto. Ele sabe que cada dia é menos um dia. Cada manhã é uma manhã passada, irrecuperável. E todas estas palavras nos inauguram como ser da fragilidade. Viver um dia é ter menos um dia. Tudo é perda e luto.Apesar de esses dados serem concretos, óbvios, é difícil para o educador trabalhar com eles: viver não é um processo de soma, mas de subtração. Ao ter que assimilar isso o tempo todo, para que o presente seja intenso, sentimos muito como viver é doído. Mas é essa fragilidade que nos torna fortes. Ser forte, inteiro, como quer a educação, é conduzir o sujeito a tomar posse de sua fragilidade. O frágil nos faz fortes. (...) É a posse do limite, da condição precária da vida que nos faz senhores do nosso próprio destino. O processo educacional está gastando muito tempo com técnicas e não dizendo nada à emoção da pessoa envolvida no processo, à pessoa que vive em mim. (QUEIRÓS, 1991 [2012], p.102) 
Impossível aqui não nos lembrarmos de Sêneca, que defendia fortemente um certo tipo de educação das sensibilidades que não negligenciasse a grande questão da certeza de nossa finitude. Em seu tratado "Sobre a Brevidade da Vida", do primeiro século da Era Cristã, podemos ler o seguinte:

É lícito afirmar que se dedicam aos verdadeiros ofícios os que querem desfrutar, todos os dias, da intimidade de Zenão, Pitágoras, Demócrito, Aristóteles, Teofrasto e de outros mestres das boas artes. Nenhum deles faltará, nenhum deles mandará embora aquele que o procurar sem deixa-lo mais feliz e mais dedicado a ele; nenhum permitirá, a quem quer que seja, sair de mãos vazias; eles podem ser encontrados por qualquer mortal, seja durante o dia, seja à noite. Nenhum deles vai te levar para a morte, todos te ensinarão a morrer. (SÊNECA, séc.I d.C. [2013], p.102. Ênfase adicionada)

Nessa bonita passagem podemos acompanhar Sêneca discorrendo sobre a prática do conhecimento, de se dar à leitura dos clássicos. Evidentemente, em seu caso, dá o exemplo dos que se dispunha naquele momento. De todas as vantagens que se poderia daí decorrer, dentre elas está a questão de saber lidar com a morte e o morrer. A companhia dos clássicos, ao invés de levar o sujeito à morte, o que para Sêneca seria algo reprovável, pelo contrário ensinaria a morrer. Ensinar a morrer? E isso se ensina? O que isso pode conter de benéfico?

Nosso senso comum contemporâneo parece estar muito distante dessa proposição de que morrer seria algo que se pudesse aprender. Quando não se ignora o fato de que irás morrer, prepara-te, pois com todas as suas forças a sua vida, pois que a vida bem vivida é chave para uma morte digna. A morte digna depende de uma vida digna. Quanto mais rápido puder transformar sua vida em dignidade, mais rápido se estará pronto para a morte quando esta, em seu capricho, se apresentar. Contra o seu poder muito pouco podemos. Só nos resta o preparo para o seu encontro.

É preciso ficar claro que a dignidade da qual temos falado tem a ver com o desejo dos sujeitos. Está ligada a um sentido de vida, mas um sentido decidido pelo sujeito e não indicado por outrem. Um longo trabalho sobre si, como muito bem nos lembra Foucault (1984 [2006]), é necessário para que o sujeito se aproxime dessa dimensão em sua vida: o encontro com um sentido do desejo. Sem esse desejo, que traz a vontade de viver, a dignidade para esse sujeito, a morte por vezes pode aparecer como preferível. A educação precisa ajudar o sujeito nessa travessia: travessia em direção ao encontro com o seu desejo.

Próximo de sua morte, o autor persistiu nessa ideia. Em seu "Manifesto por um Brasil literário", publicado na famosa Feira Literária de Paraty, a FLIP, 
de 2009 - três anos antes do falecimento do escritor -, B. C. de Queirós parece condensar a compreensão que tinha de seu próprio fazer e da relação desse fazer com as grandes questões da humanidade:

Outorgando a si mesmo o privilégio de idealizar outro cotidiano em liberdade, e movido pela intimidade maior de sua fantasia, um conhecimento mais amplo e diverso do mundo ganha corpo e se instala no desejo de homens e mulheres promovendo os indivíduos a sujeitos e responsáveis pela sua própria humanidade. (QUEIRÓS, 2009 [2012], p.118)

O sentido da educação, para B. C. de Queirós parecia estar exatamente aí: formar sujeitos que consigam trazer alternativas para a realização de seus desejos, não abrindo mão do prazer ao viver. Fundamento também de sua política.

No limite, a meta última dessa proposição seria um transbordamento da escola. Ou seja, que esse modo de entendimento da educação, claramente não restrito a apenas um recorte geracional, atingisse adultos que não necessariamente os de classes intelectualizadas. Que esse projeto impulsionasse os legisladores a baixarem o tempo da jornada de trabalho em direção à garantia de um maior tempo livre.

Com o uso do tempo livre se poderia pensar no autocultivo. Através do autocultivo se coloca em questão a subjetividade como jóia rara que merece atenção constante. Com a atitude do autocultivo virá também o inevitável incremento na autonomia da relação de cada sujeito com a tradição através de maior frequência às bibliotecas. E disso viria também a quebra do poder da mídia de massa.

\section{REFERÊNCIAS}

ARENDT, H. A Condição Humana. Trad. Roberto Raposo, posfácio de Celso Lafer. 10 ed. Rio de Janeiro: Forense Universitária, 2005.

FOUCAULT, M. Uma Estética da Existência. In: Ditos e Escritos V: Ética, sexualidade, política / Foucault. Rio de Janeiro: Forense Universitária, 2006 [1984]. p.288-294

FOUCAULT, M. História da Sexualidade: o cuidado de si (vol.3). Rio de Janeiro: Edições Graal, 1985. [1984]

FOUCAULT, M. História da Sexualidade: o uso dos prazeres (vol.2). Rio de Janeiro: Edições Graal, 1998. [1984] 
FOUCAULT, M. A Hermenêutica do Sujeito. São Paulo: Martins Fontes, 2011. [1982] FOUCAULT, M. História da Sexualidade: a vontade de saber (vol.1). Rio de Janeiro: Edições Graal, 1980. [1976]

FOUCAULT, M. Vigiar e punir: nascimento da prisão. Petrópolis: Vozes, 1984. [1975] FOUCAULT, M. História da Loucura na Idade Clássica. São Paulo: Perspectiva, 1978. [1972] LOPES, E. M. T. Da sagrada missão pedagógica. p.35-70. In: LOPES, E. M. T. (Org.). A psicanálise escuta a educação. Belo Horizonte: Autêntica, 1998.

OLIVEIRA, M. A. T. de. Pensando a História da Educação com Raymond Williams. Educação \& Realidade, Porto Alegre, v. 39, n. 1, p.257-276, jan. / mar. 2014.

QUEIRÓS, B. C. Manifesto por um Brasil literário. In: ABREU, J. (Org.). Sobre ler, escrever e outros diálogos. Belo Horizonte: Autêntica, 2012. (Texto originalmente lançado no folheto da Festa Literária de Paraty (FLIP), em julho de 2009.)

QUEIRÓS, B. C. Balanço. In: ABREU, J. (Org.). Sobre ler, escrever e outros diálogos. Belo Horizonte: Autêntica, 2012. (Originalmente publicado em: PRADO, J. \& DINIZ, J. (Orgs.). Vivências de leitura. Rio de Janeiro: Leia Brasil, 1997.)

QUEIRÓS, B. C. Foram muitos, os professores. In: ABREU, J. (Org.). Sobre ler, escrever e outros diálogos. Belo Horizonte: Autêntica, 2012. (Originalmente publicado em: ABRAMOVICH, F. (Org.). Meu professor inesquecível: ensinamentos e aprendizados contados por alguns de nossos melhores escritores. São Paulo: Gente, 1997.)

QUEIRÓS, B. C. Arte e Educação. In: ABREU, J. (Org.). Sobre ler, escrever e outros diálogos. Belo Horizonte: Autêntica, 2012. (Texto da palestra originalmente proferida no: III Encontro Estadual do Projeto Biblioteca/Vídeo-Escola, 1991.)

QUEIRÓS, B. C. Literatura, escola e democracia. In: ABREU, J. (Org.). Sobre ler, escrever e outros diálogos. Belo Horizonte: Autêntica, 2012. (Texto da palestra originalmente proferida na: II Conferência Brasileira de Educação, UFMG, 1982.)

SÊNECA, L. A. Sobre a Brevidade da Vida. Porto Alegre: L\&PM, 2013. [1ª ed. Séc. I d.C.]

SOUZA JÚNIOR, M. \& GALVÃO, A. M. O. História das disciplinas escolares e história da educação: algumas reflexões. Educação \& Pesquisa, Dez 2005, vol.31, nº.3, p.391408. Disponível em: http://www.scielo.br/scielo. Acesso em: 03 dez. 2018.

SKINNER, Q. As fundações do pensamento político moderno. São Paulo: Companhia das Letras, 1996.

Texto recebido em 12 de novembro de 2018.

Texto aprovado em 14 de dezembro de 2018. 